\title{
Electroanalytical Applications Based on Carbon Nanotube/Prussian Blue Screen-printable Composite
}

\author{
Jun Ho Shim, Jae Seon Lee, ${ }^{\dagger}$ Geun Sig Cha, ${ }^{\dagger}$ and Hakhyun Nam ${ }^{\dagger}, *$ \\ New and Renewable Energy Research Center, Ewha Womans University, Seoul 120-750, Korea \\ ${ }^{\dagger}$ Chemical Sensor Research Group, Department of Chemistry, Kwangwoon University, Seoul 139-701, Korea \\ *E-mail:namh@kw.ac.kr \\ Received February 3, 2010, Accepted March 31, 2010
}

\begin{abstract}
A single step fabrication process of carbon nanotube/Prussian Blue (CNT/PB) paste electrodes based on screen printing technology has been studied as an amperometric sensor for the determination of hydrogen peroxide and free chlorine. Compared to the classical carbon paste (CP) electrode, the CNT paste electrode greatly enhanced the response in the presence of hydrogen peroxide due to the electrocatalytic activity of the CNT. Based on the CNT/binder paste, PB was also incorporated into a network of CNT paste and characterized. The best electroanalytical properties of PB-mixed sensors to hydrogen peroxide were obtained with PB ratio of $10 \mathrm{wt} \%$ composition, which showed fast response time $\left(t_{90} \leq 5 \mathrm{~s} ; 0.2-0.3 \mathrm{mM}\right)$, low detection limit of $1.0 \mu \mathrm{M}$, good linear response in the range from $5.0 \times$ $10^{-5}-1.0 \times 10^{-3} \mathrm{~mol} \mathrm{~L}^{-1}\left(r^{2}=0.9998\right)$, and high sensitivity of $-8.21 \mu \mathrm{AmM}^{-1}$. In order to confirm the enhanced electrochemical properties of CNT/PB electrode, the sensor was further applied for the determination of chlorine in water, which exhibited a linear response behavior in the range of $50-2000 \mathrm{ppb}$ for chlorine with a slope of $1.10 \mu \mathrm{A}$ $\operatorname{ppm}^{-1}\left(r^{2}=9971\right)$.
\end{abstract}

Key Words: Carbon nanotube, Prussian Blue, Screen printing technology, Hydrogen peroxide, Chlorine

\section{Introduction}

As the demand for disposable biosensors increases in the field of point-of-care testing (POCT), ${ }^{1}$ the need for highly sensitive, reliable and economically mass producible electrodes increases. In this regards, the thick film technology, fabricating films for electronic components based on screen printing process, is one of the most efficient means of producing electrochemical biosensors owing to their small size, fast response time, high reproducibility, low cost, wide potential window, and low background currents. ${ }^{2-4}$ The mediated amperometric enzyme sensor can be prepared on the carbon paste (CP) electrode which is one of widely studied the thick-film transducer for the fabrication and application of electroanalytical biosensors. The type of each component and their respective ratios determine the electrochemical properties of resultant electrodes. ${ }^{4}$ Another critical composition is the sensing layer tightly adhered on the transducing layer. The use of thick-film technology is promising for the mass production of sensors for biological and environmental monitoring.

Since the first report in $1991,{ }^{5}$ carbon nanotubes (CNTs) have received enormous attention for the preparation of electrochemical sensors due to their unique properties. Some authors ${ }^{6,7}$ have widely reviewed the ability of CNTs to promote electron transfer reactions regarding different biomolecules and their biosensing applications such as Pt nanoparticles and CNT composite, ${ }^{8}$ modification of glassy carbon electrodes with CNT, ${ }^{9}$ and a binder-less composite CNT/graphite/enzyme mixture packed in a needle. ${ }^{10}$ Several methods have also been proposed for the immobilization of CNTs on electrochemical transducer like the CNT/epoxy composites, ${ }^{11}$ formulation of CNT/Teflon composite, ${ }^{12,13}$ CNT/Nafion association ${ }^{14}$ and CNT/chitosan system ${ }^{15}$ because they are not readily dispersed in aqueous medium. In addition, special attention has been paid to the possibilities of carbon nanotube paste (CNTP)-based electrodes in electrochemical investigations and in modern electroanalysis. Rivas group ${ }^{16-21}$ has reported on the advantages of CNTP electrode on the electrochemical behavior of different redox systems based on the use of CNTs dispersed in a mineral oil: dopamine, ascorbic acid, dopac and uric acid as well as hydrogen peroxide; ${ }^{16}$ guanine, adenine and nucleic acids; ${ }^{17}$ phenol, catechol, NADH and hydroquinone $;{ }^{18}$ epinephrine and norepinephrine $;{ }^{19}$ and glucose. ${ }^{20}$ Wang et al. reported the use of CNTP electrode for the oxidation of hemocysteine. ${ }^{22}$ Palleschi et $a l .^{23}$ published CNT paste electrode using single-wall carbon nanotubes (SWCNTs) mixed with mineral oil for the detection of hydrogen peroxide, $\mathrm{NADH}$ and dopamine. They also reported for the first time the modification of SWCNT with Prussian Blue (PB) for hydrogen peroxide detection. ${ }^{24}$ Wang et al. first proposed the screen printable CNT-based electrodes as an electrochemical transducer by hand printing on alumina ceramic plates for the detection of hydrogen peroxide, NADH and glucose. ${ }^{25}$ The handprinted electrodes were fabricated using a CNT-derived ink with isophorone solution containing several different types of binders. Considering practical utilization and mass production, these objectives of the invention in all papers cited here are often limited to be used as an efficient means of producing electrochemical biosensors because the conducting matrix/binder system plays a significant role in the mass production technology like screen printing.

PB has attractive electrocatalytic properties. ${ }^{26-29}$ Many researchers reported that $\mathrm{PB}$ exhibited high catalytic activity for the determination of hydrogen peroxide. ${ }^{27-29}$ The PB complex can exist in two different forms, i.e. insoluble $\left(\mathrm{Fe}^{\mathrm{III}}{ }_{4}\left(\mathrm{Fe}^{\mathrm{II}}\right.\right.$ 
$\left.\left.(\mathrm{CN})_{6}\right)_{3}\right)$ and soluble $\left(\mathrm{KFe}^{\mathrm{II}} \mathrm{Fe}^{\mathrm{III}}(\mathrm{CN})_{6}\right)$. PB is electrochemically reduced to Prussian white (Everitt's salt), which is capable of catalyzing the reduction of hydrogen peroxide at a low potential, behaving like a peroxidase; for this reason, it is often referred as an "artificial peroxidase". ${ }^{29}$ Hydrogen peroxide is one of the main products of the oxidase catalyzed reactions. Hence, biosensors are designed to measure hydrogen peroxide to quantify the substrate. With this excellent ability as a biosensing mediator, PB was incorporated with CNT-based electrodes by electrodeposition, ${ }^{30,31}$ blend-and-casting of $\mathrm{PB} / \mathrm{CNT}$ layer, ${ }^{32-34}$ and modification of CNT with a precipitated PB. ${ }^{35}$ However, all of them are multilayered structures formed on glassy carbon or graphite electrodes even onto the screen-printed electrodes and requires multiple steps to fabricate desired electrodes, which are not reliable and may causes increasing time and cost.

In the present work, the single step fabrication process of $\mathrm{PB} / \mathrm{CNT}$ electrode is presented for the applications of screenprinted electrodes. The novel PB/CNT paste simplifies the production process since the screen-printing process directly yields highly sensitive $\mathrm{PB} / \mathrm{CNT}$ electrode without further modification. Therefore, we believe our approach will reduce cost and time for sensor production. The screen-printed electrode based on $\mathrm{PB} / \mathrm{CNT}$ composite was evaluated in terms of amperometric responses to hydrogen peroxide and chlorine. The electrochemical activity monitored by strip-type amperometric electrodes for hydrogen peroxide and chlorine were compared to the homemade $\mathrm{CP}$ electrode. The greatly enhanced electrochemical signal will assure the possible application in biosensor and environmental monitoring. The thick film technology studied in this work has great potential in developing a mass-producible, inexpensive, mechanically robust, and disposable sensing platform.

\section{Experimental}

Reagents and solutions. All reagents were commercially available and were employed without further purification. Potassium hexacyanoferrate (III), calcium hypochlorite and ferric chloride were purchased from Sigma-Aldrich. Terpineol anhydrous was purchased from Fluka. Multi-wall carbon nanotube (Nanolab; OD $15 \pm 5 \mathrm{~nm}$, length $1-5 \mu \mathrm{m}$ ), graphite powder (Fisher), silver paste LS-506 (Asahi Chemical Research Laboratory), dielectric layer (Seoul Chemical Research Laboratory; SCR-505G solder resist ink and SH-3 hardner), polyester films $(3 \mathrm{M})$, and high ethoxyl cellulose polymer (Dow Chemical) were used in fabricating the screen-printed electrode. CNT paste was prepared at working site in our laboratory. Throughout the work, deionized water $(\geq 18 \mathrm{M} \Omega \mathrm{cm})$ further purified via a Millipore Direct-Q unit (Billerica, USA) was used. The supporting electrolyte was an aqueous solution buffered at $\mathrm{pH} 7.4$ with $0.05 \mathrm{M}$ phosphate and $0.14 \mathrm{M} \mathrm{NaCl}$. Stock solutions of hydrogen peroxide were prepared daily in buffer solution and stored in the dark at $4{ }^{\circ} \mathrm{C}$ before use. Residual chlorine analysis was carried out in $0.05 \mathrm{M}$ phosphate containing $0.14 \mathrm{M} \mathrm{NaCl}$ solution at $\mathrm{pH} 6.9$.

Instrumentation. Cyclic voltammogram (CV) measurements were performed with an EG\&G PAR (Princeton, USA) Model
273A potentiostat/galvanostat controlled by an IBM PC with an EG\&G M270 software program. Eight channel multipotentiostat (ELBIO cDAQ-1604, Korea) was used to run currenttime responses. All measurements were conducted using a three-electrode configuration except for the detection of residual chlorine. Scanning electron micrographs (SEMs) were obtained with a Hitachi Model S-2700 microscope (Tokyo, Japan). A semi-automated screen-printer (LS-150 NEW LONG, Tokyo, Japan) and a set of stencils (Daeshin Co., Korea) patterned for the electrodes were used for constructed planar arrays of thirty electrodes. The resultant planar arrays were used to produce disposable strip electrodes. A 3-roll mill (EXAKT 50, EXAKT Co., Germany) was used for mixing and milling of CNT with polymer binder.

Preparation of CNTP. All printing composites were prepared at room temperature. Polymer binder was diluted by thoroughly mixing $25 \mathrm{wt} \%$ of high ethoxyl cellulose with $75 \mathrm{wt} \%$ of terpineol in a vial $(3 \mathrm{~cm} \times 5 \mathrm{~cm})$ for $30 \mathrm{~min}$, and then CNT was carefully added to the vial with mechanical stirrer (IKA, USA). The preliminary respective inks were then homogeneously admixed in 3-roll mill (below 10- $\mu$ m interval between rolls) for $30 \mathrm{~min}$. Three different mixed proportions were prepared by varying the amount of CNT; 10,33 , and 50 (wt \%). Other pastes with different sensor materials (graphite or PB) were prepared in a similar fashion. The viscosity of homogenized composites was adjusted with terpineol. The achieved pastes were stored in a refrigerator at $5-10^{\circ} \mathrm{C}$ before use.

Construction of the amperometric transducer. The thick-film amperometric electrodes were fabricated using screen-printing technology. The substrate of the screen-printed CNTP electrode was $0.5 \mathrm{~mm}$ thick flexible PE films which were cut into $10 \mathrm{~cm} \times$ $15 \mathrm{~cm}$ and thermally treated at $130{ }^{\circ} \mathrm{C}$ for 3 hours before the printing to prevent further thermal shrinkage in the following process. Three silver lines (electrical connection and reference electrode), CNT pattern (for working and counter electrode) and a dielectric layer were sequentially screen-printed onto the thermally pretreated PE film using the stencils corresponding to each layer pattern. Each pattern was dried at $130^{\circ} \mathrm{C}$ for $13 \mathrm{~min}$ after the printing. The overall dimension of individual screenprinted CNTP electrode was $8 \mathrm{~mm} \times 34 \mathrm{~mm}$. The projected area of the round-shaped working electrode was $0.07 \mathrm{~cm}^{2}$. Thirty strips were printed on one film. $\mathrm{The} \mathrm{Ag} / \mathrm{AgCl}$ reference electrode was prepared by oxidative treatment using $3.0 \mathrm{M} \mathrm{FeCl}_{3}$ solution on the dried silver paste for 10 minutes. The surface of the printed electrodes was rinsed thoroughly with doubledistilled water prior to use.

\section{Results and Discussion}

Structure characters of thick-film electrodes. The CNTP electrodes in this study were prepared by mixing different weight percentages of CNT with polymer binder, i.e., 10, 33, and $50(\mathrm{wt} \%)$ ratios of $\mathrm{CNT} /$ binder. Beside these ratios in paste blending, the ink containing over 50 (wt \%) of CNT in the same ethoxyl cellulose level can not be used for the screen printing purpose, because the large porous CNT requires extremely high amount of polymer/solvent mixture, which allows surface blocking for the electron transfer. It is important to 


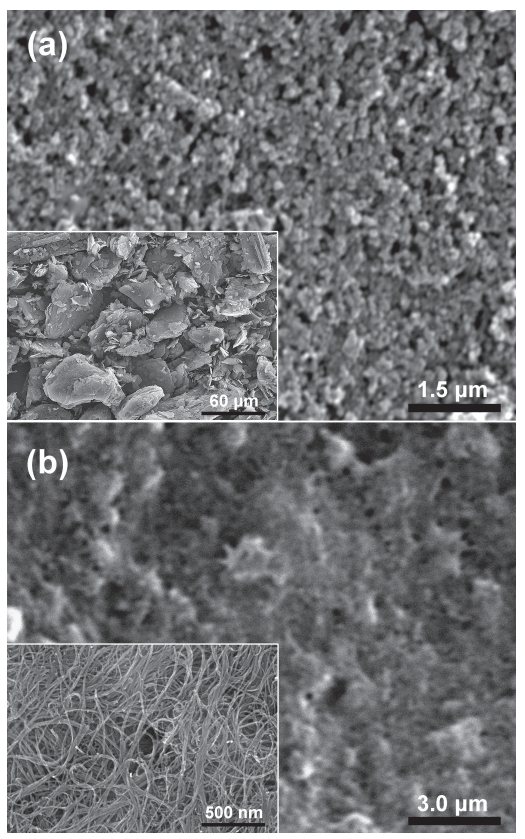

Figure 1. SEM images of the (a) graphite and (b) CNTP electrodes. Insets are the powders of respective graphite and CNT.

describe that the electrochemical sensor properties are corresponded to background current and capacitance.

Figure 1 shows the typical morphological features of graphite and CNTP electrodes prior to the electrochemical measurements. SEM image (Figure 1a) of screen-printed electrode displays a surface of the graphite electrode obtained by dispersion of graphite within the ethoxyl cellulose binder ( $50 \mathrm{wt} \%)$. The electrode surface is formed by regularly shaped micrometer sized graphite flake corresponding to the graphite powder in inset (Figure 1a). A homogeneous distribution of CNT within the polymer binder ( $50 \mathrm{wt} \%$ ) after printing on the substrate can be observed in Figure 1b. The CNT-based electrode shows a more fine surface morphology than that of graphite in micrometer scale. The inset (Figure 1b) shows the nanotube powder used in this study. The quality of printed electrode was not damaged by the use of a CNT-based ink. The screen-printed CNTP electrode remained like a hard shell and stable after several washings and electrochemical measurements.

Electrochemical behavior of transducers. The electrolytes at CNTP electrode are likely to access the interior surface leading to high differential capacitance compared with graphite electrode since $\mathrm{CNT}$ is a highly porous material. In this respect, we first explored the electrochemical response of electrodes modified with CNT and graphite in a phosphate buffer solution containing $\mathrm{Fe}(\mathrm{CN})_{6}^{3 / 4-}$ couple between 0.8 and $-0.4 \mathrm{~V}$ at a scan rate of $50 \mathrm{mV} \mathrm{s}^{-1}$. The cyclic voltammograms of the electrodes printed with the paste formulated with varying CNT/polymer binder ratio $(10,33$, and 50 (wt \%)) and graphite/polymer binder (50 wt \%) are shown in Figure 2. When the CNT was used instead of the graphite, we observed greatly increased redox activities. It is important to remark that the excellent electrocatalytic properties of the carbon composite material were observed with thick-film electrode containing CNT. As presented

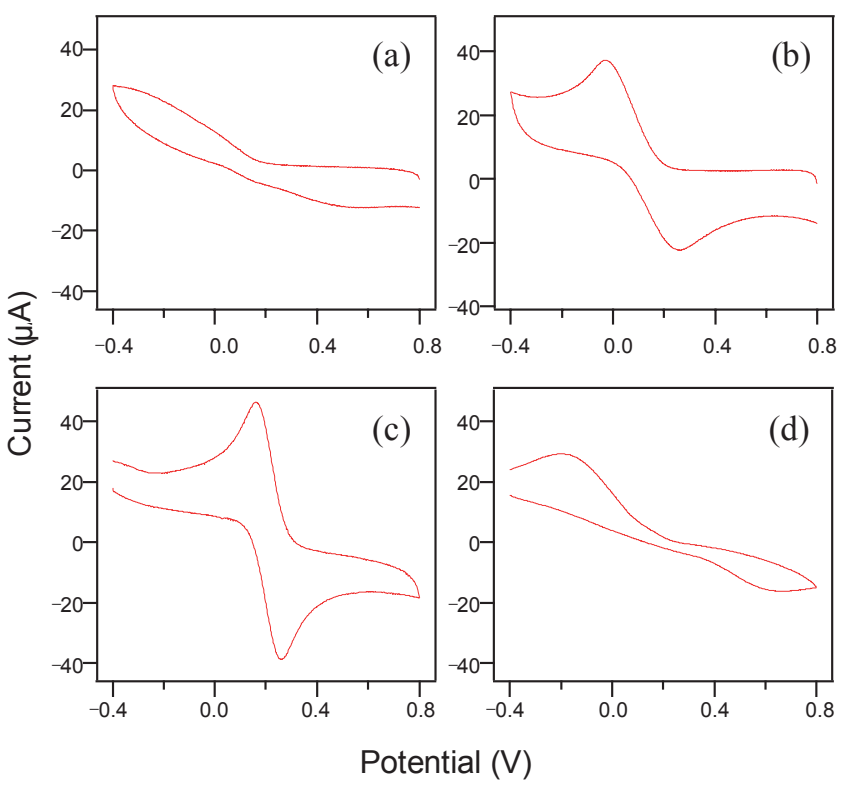

Figure 2. Cyclic voltammograms obtained at CNTP and graphite electrode in $0.5 \mathrm{mM}$ potassium ferricyanide with scan rate, $50 \mathrm{mV} \mathrm{s}^{-1}$ : (a) CNT ratio (wt \%) of 10; (b) 33; (c) 50; and (d) graphite ratio (wt \%) of 50 .

Table 1. Peak potential separation $\left(\Delta E_{\mathrm{p}}\right)$ and peak currents $\left(I_{\mathrm{pa}} ; I_{\mathrm{pc}}\right)$ at the CNTP and graphite electrode in $0.5 \mathrm{mM} \mathrm{K}_{3} \mathrm{Fe}(\mathrm{CN})_{6}$ containing $0.1 \mathrm{M} \mathrm{KCl}^{a}$

\begin{tabular}{|c|c|c|c|c|}
\hline & \multicolumn{3}{|c|}{$\% \mathrm{CNT}$ in the ink formulation } & \multirow{2}{*}{$\frac{\% \text { Graphite }}{50}$} \\
\hline & 10 & 33 & 50 & \\
\hline$\Delta E_{\mathrm{p}}(\mathrm{mV})$ & 543 & 208 & 85.1 & 782 \\
\hline$I_{\mathrm{pa}}(\mu \mathrm{A})$ & 6.6 & 25.9 & 40.9 & 1.2 \\
\hline$I_{\mathrm{pc}}(\mu \mathrm{A})$ & 19.8 & 37.4 & 42.8 & 20.8 \\
\hline$I_{\mathrm{pa}} / I_{\mathrm{pc}}$ & 0.33 & 0.69 & 0.96 & 0.06 \\
\hline
\end{tabular}

${ }^{\bar{a}}$ Potential range from $0.8 \mathrm{~V}$ to $-0.4 \mathrm{~V}$ (vs. $\left.\mathrm{Ag} / \mathrm{AgCl}\right)$. Scan rate is $50 \mathrm{mV} \mathrm{s}^{-1}$.

in Table 1, the cyclic voltammogram obtained with the CNTP electrode containing the least amount of binder ( $50 \mathrm{wt} \%$ of CNT) exhibited improved reversibility in terms of $\Delta E_{\mathrm{p}}$ and peak current $\left(I_{\mathrm{p}}\right)$ for $\mathrm{Fe}(\mathrm{CN})_{6}{ }_{6}^{3 / 4-}$ couple. It can be seen that the electron transfer of $\mathrm{Fe}(\mathrm{CN})_{6}{ }^{3 / 4}$ redox couple at $\mathrm{CNTP}$ is much faster $\left(\Delta E_{\mathrm{p}}=85.1 \mathrm{mV}\right.$ of Figure $\left.2 \mathrm{c}\right)$ than at graphite $\left(\Delta E_{\mathrm{p}}=782 \mathrm{mV}\right.$ of Figure 2d). Apparently, due to the CNT dimensions, these results demonstrate that the improved electrocatalytic activity of CNT presents on its surface; the redox couples in the proximity of the electrode may easily transfer the electrons to the needle-like CNT exposed on the surface of the electrode, resulting in enhanced electrocatalytic property.

Since hydrogen peroxide is an important molecule involved in numerous enzymatic processes, the development of new methodologies for the sensitive and selective hydrogen peroxide determination is crucial. Figure 3 shows a typical current response to hydrogen peroxide as the compositions of the CNTand graphite-based thick-film electrodes. The amperometric responses were operated at a potential of $+0.65 \mathrm{~V}$. The linear ranges of each electrode were between $5 \times 10^{-5} \mathrm{M}$ and $1 \times 10^{-3} \mathrm{M}$ 

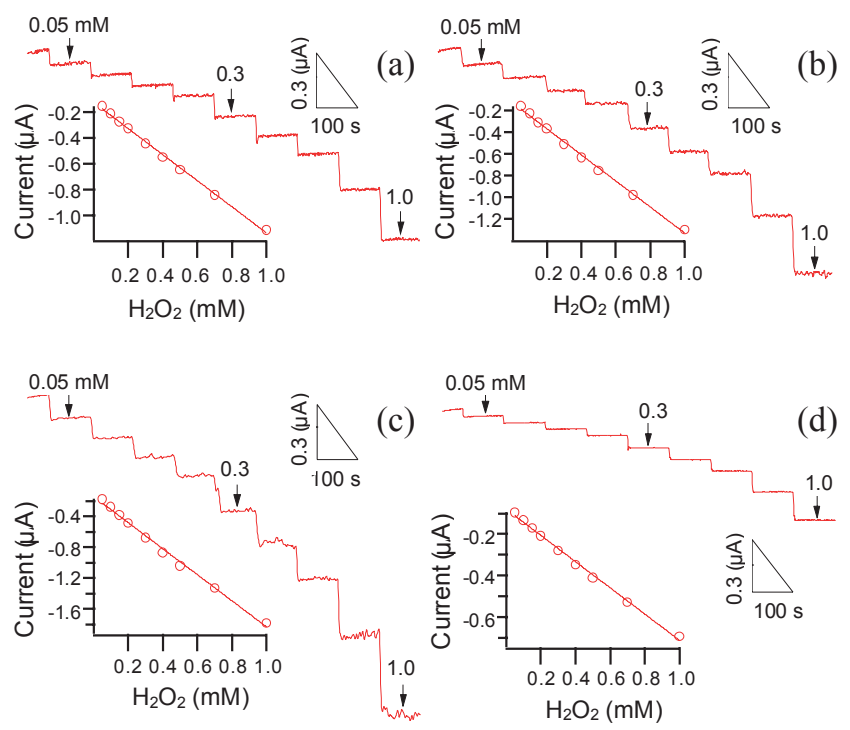

Figure 3. Current-time response obtained on increasing the hydrogen peroxide concentration stepwise from 50 to $1000 \mu \mathrm{M}$ : a, CNT ratio (wt \%) of $10 ; \mathrm{b}, 33$; c, 50; and d, graphite ratio (wt \%) of 50. Applied potential was $0.65 \mathrm{~V}(v s . \mathrm{Ag} / \mathrm{AgCl})$ in $0.05 \mathrm{M}$ phosphate buffer $(\mathrm{pH}$ 7.4).

of hydrogen peroxide, and the slopes of the calibration: -1.02 $\mu \mathrm{A} / \mathrm{mM}\left(\mathrm{r}^{2}=0.9986\right)$ for $10 \mathrm{wt} \%$ of CNT; $-1.20 \mu \mathrm{A} / \mathrm{mM}\left(\mathrm{r}^{2}=\right.$ $0.9982)$ for $33 \mathrm{wt} \%$ of $\mathrm{CNT} ;-1.69 \mu \mathrm{A} / \mathrm{mM}\left(\mathrm{r}^{2}=0.9970\right)$ for $50 \mathrm{wt} \%$ of CNT; and $-0.63 \mu \mathrm{A} / \mathrm{mM}\left(\mathrm{r}^{2}=0.9979\right)$ for $50 \mathrm{wt} \%$ of graphite. The obtained results shown in Figure 2 prove that the CNTP electrode based on CNT ratio of the $50 \mathrm{wt} \%$ exhibited the most effective catalytic activity on the electrode surface.

Characterization of PB-derived CNTP electrode. CNTP electrode incorporated with varying weight percentage of $\mathrm{PB}$ were prepared as described in experimental section, and their electrochemical characteristic was evaluated by recording cyclic voltammogram (scan rate of $60 \mathrm{mV} \mathrm{s}^{-1}$ ) of the working electrode in $1.0 \mathrm{M} \mathrm{KCl}$ solution. Figure 4 shows typical quasi reversible redox peaks which correspond to the redox reaction between $\mathrm{Fe}^{\mathrm{III}}\left[\mathrm{Fe}^{+2}(\mathrm{CN})_{6}\right]^{-1}$ and $\mathrm{Fe}^{\mathrm{II}}\left[\mathrm{Fe}^{+2}\left(\mathrm{CN}_{6}\right)\right]^{-2}$, indicating that the redox reaction of $\mathrm{PB}$ occurs reversibly within the CNTP electrode.

The PB/CNT thick-film electrode has also been investigated further for the determination of hydrogen peroxide in $0.05 \mathrm{M}$ phosphate buffer containing $0.1 \mathrm{M} \mathrm{KCl}$ as supporting electrolyte. As displayed in Figure 5, the increase in PB ratio at the $\mathrm{CNT} /$ binder composite substantially enhances the amperometric responses of hydrogen peroxide indicating that the PB catalyzes the electrochemical process at the surface of the electrode. The sensitivity to the change in the concentration of hydrogen peroxide (between $5 \times 10^{-5} \mathrm{M}$ and $1 \times 10^{-3} \mathrm{M}$ ): $-0.62 \mu \mathrm{A} / \mathrm{mM}$ for graphite $(50 \mathrm{wt} \%) ;-1.49 \mu \mathrm{A} / \mathrm{mM}$ for CNT $(50 \mathrm{wt} \%) ;-1.68$ $\mu \mathrm{A} / \mathrm{mM}$ for $\mathrm{PB}$ ratio $(\mathrm{R}$, wt $\%)$ of $\mathrm{R}=0.1 ;-4.53 \mu \mathrm{A} / \mathrm{mM}$ for $\mathrm{R}=1$; and $-8.21 \mu \mathrm{A} / \mathrm{mM}$ for $\mathrm{R}=10$. The optimized composition of CNT (50 wt \%) was used to examine the comparative performance of hydrogen peroxide at the PB-derived CNTP electrode.

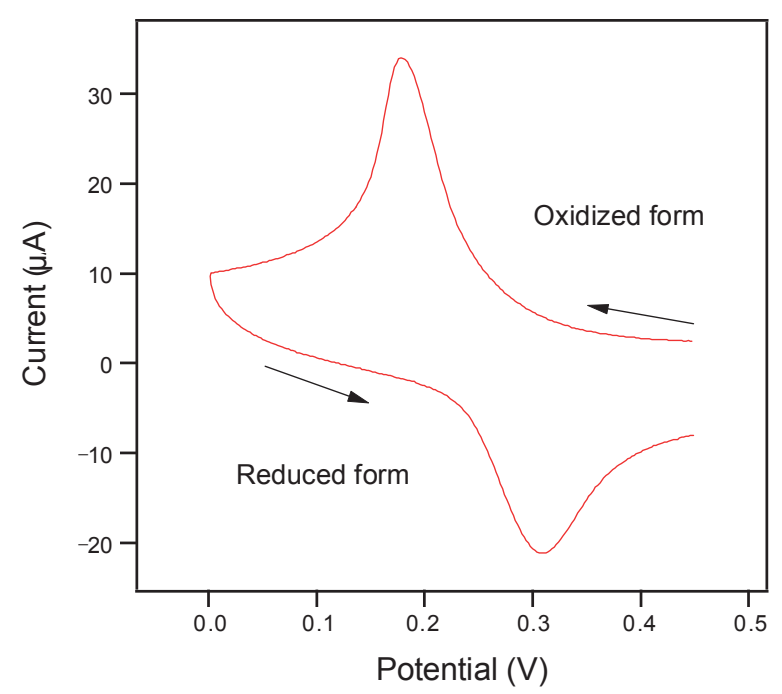

Figure 4. Cyclic voltammogram obtained at $10 \mathrm{wt} \%$ PB-mixed CNTP electrode in $1.0 \mathrm{M} \mathrm{KCl}\left(\mathrm{pH} \mathrm{4.0)}\right.$. Scan rate is $60 \mathrm{mV} \mathrm{s}^{-1}$.

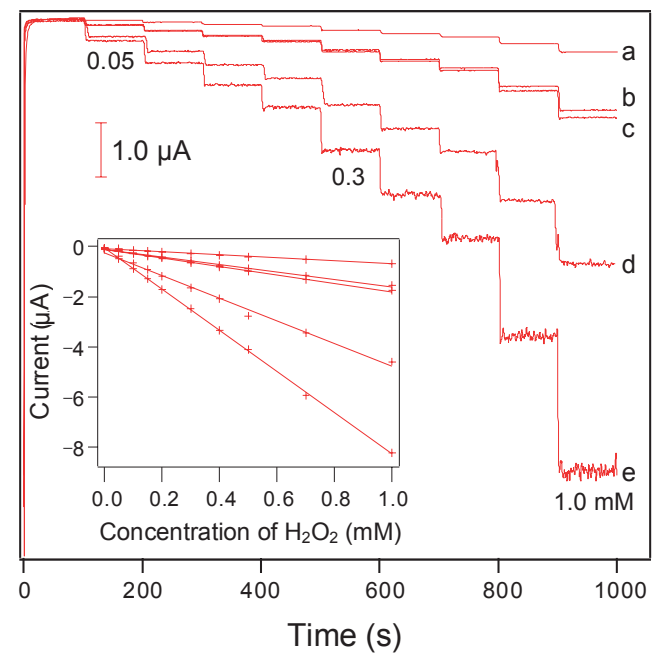

Figure 5. Current-time response obtained on increasing hydrogen peroxide concentration stepwise from 50 to $1000 \mu \mathrm{M}$ : a, graphite; b, PB ratio (wt \%) of $0 ; \mathrm{c}, 0.1 ; \mathrm{d}, 1$; and e, 10. Applied potential was $0.65 \mathrm{~V}(v s . \mathrm{Ag} / \mathrm{AgCl})$ in $0.05 \mathrm{M}$ phosphate buffer ( $\mathrm{pH} 7.4)$.

Characterization of PB-CNTP electrode for chlorine detection. In order to confirm the enhanced electrochemical properties of PB mixed thick-film electrode, we also applied the electrode for the determination of residual chlorine. Chlorine is extensively used as a disinfectant for drinking water and swimming pool as well as strong oxidizing agent in various manufacturing processes. Its concentration must be strictly regulated at the purification plant of public water systems and swimming pools since chlorine is highly toxic and reacts with other contaminants to produce carcinogens. Conventional electrochemical analysis for residual chlorine has been carried out on the noble metals like Pt or Au electrodes. ${ }^{36-38}$ The screen-printed CNTP electrode would be more advantageous in the detection of chlorine over those conventional electrodes; it is much less expensive than noble metals and suitable for mass production. 


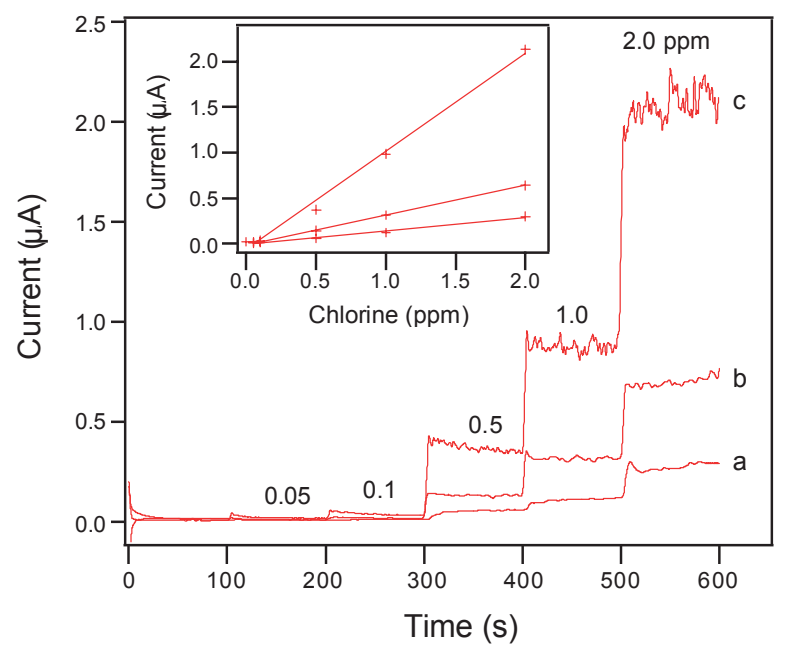

Figure 6. Current-time response obtained on increasing residual chlorine concentration: a, graphite; b, CNT only; and c, CNT with PB ratio of $10 \mathrm{wt} \%$. Applied potential was $-0.1 \mathrm{~V}(\mathrm{vs} . \mathrm{Ag} / \mathrm{AgCl})$ in $0.05 \mathrm{M}$ phosphate buffer (pH 6.9) containing $0.1 \mathrm{M} \mathrm{KCl}$.

The proposed mechanism of hypochlorous acid to hydroxide ions is as follows: ${ }^{39}$

$$
2 \mathrm{Ag}^{+}+\mathrm{Cl}^{-}+\mathrm{HOCl} \rightarrow 2 \mathrm{AgCl}+\mathrm{OH}^{-}
$$

The screen-printed CNTP electrodes in both the presence and absence of PB were investigated as a possible new transducer for the determination of free chlorine. Sequentially addition of chlorine stock solution was made to the $0.05 \mathrm{M}$ PBS buffer (pH 6.9) since $\mathrm{p} K_{\mathrm{a}}$ of $\mathrm{HOCl}$ was assumed to be 7.48 at $25^{\circ} \mathrm{C}$. Figure 6 shows the dynamic and calibration curves (inset) of the respective three different electrodes prepared with (a) graphite, (b) CNT and (c) PB (10 wt \%) mixed CNT from 50 $2000 \mathrm{ppb}$. The analytical performance of the $\mathrm{PB} / \mathrm{CNT}$ electrode (curve c) was evaluated: sensitivity of $1.10 \mu \mathrm{A} / \mathrm{ppm}$; detection limit of $\leq 100 \mathrm{ppb}$; response time, $t_{90 \%}=c a .7 \mathrm{~s}$; and reliable linear dynamic range $\left(50-2000 \mathrm{ppb}, \mathrm{r}^{2}=9971\right)$. It is noted that the obtained result is even three times bigger sensitivity than that of CNTP electrode $(0.33 \mu \mathrm{A} / \mathrm{ppm}$, curve b). Compared with CNT-derived electrodes, however, the sensitivity $(0.15$ $\mu \mathrm{A} / \mathrm{ppm}$ ) of graphite electrode (Figure $6 \mathrm{a}$ ) was much inferior with slow response $\left(t_{90 \%}=c a .15 \mathrm{~s}\right)$ and high detection limits $(>1000 \mathrm{ppb})$. As a result, considering that the environmentally meaningful range of residual chlorine is in $10^{-5}-10^{-2} \mathrm{M}$, the sensitivity and the detection limits of PB mixed CNT-based electrode shall find useful applications in environmental residual chlorine monitoring.

\section{Conclusions}

In this work, CNT-derived paste electrodes have been developed and used to prepare screen printing type electrode system. CNT was blended with suitable polymer binder in varying ratios, and their electrochemical properties in the printed electrode format have been examined. Cyclic voltammograms of the CNT-derived electrodes in $\mathrm{Fe}(\mathrm{CN})_{6}^{3 / 4-}$ redox couple in aqueous solution exhibited quasi-reversible redox peaks while the conventional graphite thick-film ones did not, implying that the electron transfer kinetics at the CNT-based electrode surface was more favorable than the graphite-based. To further enhance the performance of CNT-based electrodes, PB was mixed with $\mathrm{CNT}$ in different ratios, and their response to hydrogen peroxide was examined. In addition, the screen printed $\mathrm{PB} / \mathrm{CNT}$ paste electrode has been utilized to determine residual chlorine in the 50 - 2000 ppb range. The overall results clearly demonstrated the advantage of CNT-derived electrodes over conventional graphite-derived ones in the detection of redox species.

Acknowledgments. H. Nam gratefully acknowledges the financial support from Kwangwoon University in 2007. J. H. Shim was supported by RP-Grant 2009 of Ewha Womans University.

\section{References}

1. Wang, J. Biosens. Bioelectron. 2006, 21, 1887.

2. Alvarez-Icaza, M.; Bilitewski, U. Anal. Chem. 1993, 65, 525A.

3. Galán-Vidal, C. A.; Muñoz, J.; Domínguez, C.; Alegret, S. Trends. Anal. Chem. 1995, 14, 225.

4. Švancara, I.; Vytřas, K.; Barek, J.; Zima, J. Crit. Rev. Anal. Chem. 2001, 31, 311.

5. Iijima, S. Nature 1991, 354, 56.

6. Wang, J. Electroanalysis 2005, 17, 7.

7. Fernández-Abedul, M. T.; Costa-García, A. Anal. Bioanal. Chem. 2008, 390, 293.

8. Hrapovic, S.; Liu, Y.; Male, K. B.; Luong, J. H. T. Anal. Chem. 2004, 76, 1083.

9. Dai, Y.; Shiu, K. Electroanalysis 2004, 16, 1697.

10. Wang, J.; Musameh, M. Analyst 2003, 128, 1382.

11. Gojny, F. H.; Nastalczyk, J.; Roslaniec, Z.; Schulte, K. Chem. Phys. Lett. 2003, 370, 820.

12. Wang, J.; Musameh, M. Anal. Chem. 2003, 75, 2075.

13. Wang, J.; Musameh, M. Anal. Lett. 2003, 36, 2041.

14. Wang, J.; Musameh, M.; Lin, Y. J. Am. Chem. Soc. 2003, 125, 2408.

15. Zhang, M.; Smith, A.; Gorski, W. Anal. Chem. 2004, 76, 5045.

16. Rubianes, M. D.; Rivas, G. A. Electrochem. Commun. 2003, 5, 689.

17. Pedano, M. L.; Rivas, G. A. Electrochem. Commun. 2004, 6, 10.

18. Rubianes, M. D.; Rivas, G. A. Electroanalysis 2005, 17, 73.

19. Chicharro, M.; Sánchez, A.; Bermejo, E.; Zapardiel, A.; Rubianes, M. D.; Rivas, G. A. Anal. Chim. Acta 2005, 543, 84.

20. Luque, G. L.; Ferreyra, N. F.; Rivas, G. A. Microchim. Acta 2006, $152,277$.

21. Rivas, G. A.; Rubianes, M. D.; Pedano, M. L.; Ferreyra, N. F.; Luque, G. L.; Rodríguez, M. C.; Miscoria, S. A. Electroanalysis 2007, 19, 823.

22. Lawrence, N. S.; Deo, R. P.; Wang, J. Talanta 2004, 63, 443.

23. Valentini, F.; Amine, A.; Orlanducci, S.; Terranova, M. L.; Palleschi, G. Anal. Chem. 2003, 75, 5413.

24. Ricci, F.; Amine, A.; Moscone, D.; Palleschi, G. Anal. Lett. 2003, 36,1921

25. Wang, J.; Musameh, M. Analyst 2004, 129, 1.

26. Neff, V. D. J. Electrochem. Soc. 1978, 125, 886.

27. Karyakin, A. A.; Puganova, E. A.; Budashov, I. A.; Kurochkin, I. N.; Karyakina, E. E.; Levchenko, V. A.; Matveyenko, V. N.; Varfolomeyev, S. D. Anal. Chem. 2004, 76, 474.

28. Karyakin, A. A.; Gitelmacher, O. V.; Karyakina, E. E. Anal. Chem. 1995, 67, 2419.

29. Karyakin, A. A.; Karyakina, E. E. Sens. Actuators B 1999, 57, 268.

30. Li, Z.; Chen, J.; Li, W.; Chen, K.; Nie, L.; Yao, S. J. Electroanal. Chem. 2007, 603, 59. 
31. Zeng, J.; Wei, W.; Liu, X.; Wang, Y.; Luo, G. Microchim. Acta 2008, 160, 261.

32. Zhang, Y.; Wen, Y.; Liu, Y.; Li, D.; Li, J. Electrochem. Comm. 2004, 6, 1180 .

33. Zhai, X.; Wei, W.; Zeng, J.; Liu, X.; Gong, S. Anal. Lett. 2006, 39, 913.

34. Zhu, L.; Zhai, J.; Guo, Y.; Tian, C.; Yang, R. Electroanalysis 2006, $18,1842$.

35. Arvinte, A.; Rotariu, L.; Bala, C.; Gurban, A. M. Bioelectrochem.
2009, 76, 107.

36. Jin, J.; Suzuki, Y.; Ishikawa, N.; Takeuchi, T. Anal. Sci. 2004, 20, 205.

37. Fumihiro, K.; Umeda, M.; Yamada, A. Anal. Chim. Acta 2005, 537, 293.

38. Kishioka, S.-Y.; Kosugi, T.; Yamada, A. Electroanalysis 2005, 17, 724.

39. Okumura, A.; Hirabayashi, A.; Sasaki, Y.; Miyake, R. Anal. Sci. 2001, 17, 1113. 